\title{
Correction to: Enhancing security and privacy of images on cloud by histogram shifting and secret sharing
}

\author{
Min-Ying Wu ${ }^{1} \cdot$ Min-Chieh Yu ${ }^{1} \cdot J^{\prime}$ enq-Shiou Leu ${ }^{1}$ (D) \\ Sheng-Kai Chen ${ }^{1}$
}

Published online: 22 November 2017

(C) Springer Science+Business Media, LLC, part of Springer Nature 2017

\section{Correction to: Multimed Tools App \\ https://doi.org/10.1007/s11042-017-5306-5}

In the original publication, figure labels $\mathbf{a}$ and $\mathbf{b}$ of Fig. 11 were missing. The original article has been corrected.

\section{Jenq-Shiou Leu}

jsleu@mail.ntust.edu.tw

Min-Ying Wu

M10202127@mail.ntust.edu.tw

Min-Chieh Yu

D10002103@mail.ntust.edu.tw

Sheng-Kai Chen

M10302147@mail.ntust.edu.tw

1 Department of Electronic and Computer Engineering, National Taiwan University of Science and Technology, Taipei, Taiwan 